\title{
Editorial statement: Why do we need a European Journal of Government and Economics?
}

Diego Varela, University of A Coruña, Spain

Giacomo Benedetto, Royal Holloway, University of London, United Kingdom

José Manuel Sánchez-Santos, University of A Coruña, Spain

\begin{abstract}
In this editorial statement we explain the reasons for the creation of the European Journal of Government and Economics. We argue that there is a general shortage of academic journals. Although the new journal we are starting will not solve or significantly reduce this problem, it will represent a marginal step in the right direction. We also explain our views regarding some important aspects of the journal's policy, such as indexing and open access.
\end{abstract}

DOI: https://doi.org/10.17979/ejge.2012.1.1.4273 


\section{Introduction}

When we informed our colleagues about our intention to create the European Journal of Government and Economics (EJGE), we found mixed reactions. On the one hand, established academics that had no difficulty in publishing their research in major journals wondered why we would need another journal, but they were ready to invest in the new project. On the other hand, junior academics that had difficulties in getting their work published could potentially benefit more from the creation of a new journal, but at the same time were more concerned about the risks involved in such an initiative. But all of them offered their support for the new venture.

The list of colleagues that have accepted to be members of the editorial board of the journal provides a good representation of both kinds of profiles, and of the journal's cross-disciplinary and international vocation. The list includes young and well as more established researchers, political scientists and economists working in academia and public policy. It includes colleagues from a dozen different countries. We are grateful to all of them.

So far as the scope of the journal is concerned, EJGE aims to be an international journal for peer reviewed research on all aspects of government and economics. EJGE is particularly interested in current issues regarding the interrelationship between the fields of government and economics, from the influence of government on the economy (economic policy) to economic explanations of government and politics (public choice). It is also particularly interested in questions directly or indirectly related to Europe. Contributions will be valued by the substantial relavance of their research questions as well as their originality. The latter may consist in the development of new models to explain existing data, the aplication of existing models to new data sets, or a combination of both.

Some of the points raised above merit additional clarification. On the one hand, it should be noted that the European focus of the journal is not limited to EU-level issues, but also includes national and subnational questions, and the papers included in this first number are a good indication of this. On the other hand, although the journal aims to strengthen the link between theory and empirical evidence by encouraging model-based research, there is nothing intrinsically quantitative or qualitative about this approach. But a basic premise is that the papers should deal with some empirically falsifiable hypothesis about the observable world, be it political or economic.

\section{The shortage of academic journals}

The creation of this new journal is based on the belief that there is a general shortage of journals, and that this shortage is hindering the dissemination of existing research and, what is more serious perhaps, discouraging research in the first place. The shortage or abundance of journals is measured by price and in the case of academic publishing, the price for authors is not only easy to measure because it is not only paid in money, but also in terms of waiting. Of course, this general shortage is not felt in the same way by everyone, as the reactions to the announcement of the journal indicate. It is particularly younger academics or academics from non-anglophone countries that have greater difficulties to get their work published by internationally recognised high-impact journals.

Academic impact is often only computed for a limited number of high quality journals. This does not mean that other journals do not make an impact. It just means that they are excluded because thay do not meet a minimum standard. Currently, such minimum standard is the inclusion in ISI's Journal of Citation Reports (JCR). Much like minimum wage requirements do not affect individuals and regions equally, JCR standards will have a differential effect on authors and 
regions. The JCR minimum standard will have no effect on many established academics from anglophone countries, whose contributions will be valued by their academic impact. However, for those academics and whole regions for which the bar is too high, such minimum standards will mean a sort of censorship.

It would be naïve to think that the creation of this journal will resolve the general shortage of academic journals or have any significant impact on the price of publishing. The main reason is the journal's broad scope and international vocation encompassing political and economic science, which means that it will represent a negligible fraction of the relevant market. As a mere price taker, EJGE does not aspire to change the world but to have a marginal contribution in the right direction. In order to do so, it will have to comply with the existing quality standards, and proper indexing is one of them.

\section{Indexing}

In a recent paper one of the editors investigates to what extent ISI Web of Science (WoS) indexing contributes to the impact of an academic paper by analysing the results of a natural experiment (Varela, 2012). The statistical tests indicate a significant effect of ISI indexing on the number of citations received by individual papers, which could be increased by a factor of two. The conclusion is that ISIindexing does not simply provide an objective measure of academic impact, but also affects academic impact itself. This is so even in the case of papers that are covered by other major indexing and search services such as Scopus or Google Scholar, which means that in spite of the increasing competition from alternative providers, there is still no full substitute for the ISI Web of Science.

If a journal indexing service has the power to multiply the academic impact of a journal by two, and indexing by other providers cannot compensate for that, then it has an extraordinary amount of power. This result may have policy implications for public authorities that go beyond the scope of this editorial statement, but also has practical implications for us as editors, and we take good note of them.

\section{Open access}

One of the distinctive features of this journal is its open-access (OA) policy, which is believed to have a significantly positive effect on academic impact. Most analyses compare the citation rates of articles that have been made open access by their authors with other articles published in the same journals that have not been made open access, finding significant statistical difference in the average citation rates, and conclude that there is a causal effect of open access on the academic impact of a paper (eg Antelman, 2004). But the results of such analyses may be biased if assignment to the treatment group (in this case, open-access) is not random but based on self-selection by the authors, which is not independent from potential outcomes in terms of academic impact. As a result, the observed difference in average academic impact may not be a good indicator of the average treatment effect on the treated because it will also include what is known as selection bias (Angrist and Pischke, 2009). It could happen, for instance, that authors who choose to make their papers open-access may be those most concerned with their academic impact, and probably use other means in parallel to increase the impact of their papers, whose effect will be confused with that of open access.

Randomised experiments such as those used in the natural sciences play an important role in uncovering causal effects, because random assignment solves the selection problem by making selection independent of potential outcomes (Angrist and Pischke, 2009). A recent randomized controlled trial of open access publishing, involving 36 participating journals in the sciences, social sciences, and humanities, reports that articles placed in the open access condition $(n=712)$ 
received significantly more downloads and reached a broader audience within the first year, yet were cited no more frequently, nor earlier, in ISI-indexed journals than subscription-access control articles $(n=2533)$ within 3 years. This contradictory result may be explained by social stratification, a process that concentrates scientific authors at a small number of elite research universities with excellent access to the scientific literature (Davis, 2011).

But open-acces journals also have disadvantages vis-à-vis those hosted by commercial publishers. Prominently among them is the fact that open-access journals give up a precious source of finance, namely the subscription fees paid by university libraries. Better finance allows for better services such as proofreading and copyediting.

It is not for ideological but for practical reasons that we start this project as an open-access journal, and we do not exclude that at any point in the future the journal, if successful and if the market allows, might migrate to a commercial publisher's platform. That is happening at the moment with some old Spanish journals, but thinking about that at this early point might be like the milkmaid's tale. At this moment we are only thinking about adding an option for colleagues to be able to publish their research and doing it as well as we can so that the journal has a high impact, and open access is just an aid in this regard.

\section{Conclusion}

With this editorial statement we have wanted to express the reasons that have led us to the creation of this new journal and explain some of its main defining features. However, the journal has a life of its own. Its evolution will be determined by the contributions of colleagues.

\section{References}

Angrist, Joshua D. and Jörn-Steffen Pischke (2009) Mostly harmless econometrics: An empiricist's companion. Princeton, NJ: Princeton University Press.

Antelman, Kristin (2004) 'Do open-access articles have a greater research impact?', College \& Research Libraries 65(5): 372-82.

Davis, Phillip M. (2011) 'Open access, readership, citations: a randomized controlled trial of scientific journal publishing', The FASEB Journal 25(7): 2129-34.

Varela, Diego (Forthcoming) 'The contribution of ISI indexing to a paper's citations: Results of a natural experiment', European Political Science. 